\title{
Design of a Flange Socket Mold and Improvement of Production Process
}

\author{
Chen Wei, Chen Dan
}

\author{
Guangdong University of Science \& Technology, No.99 Xihu Road, Dongguan, Guangdong, \\ 523083, China \\ 278811242@qq.com
}

Keywords: Flange socket, Plastic forming, Numerical simulation, Mold design.

\begin{abstract}
Flange socket is a socket fittings which require a higher production process, and has a large market demand. The complex external shape, high precision connecting parts are very difficult to process. The traditional production engineering caused a great waste of materials and is very low efficient, and the work piece is easy to produce stress concentration. The cold extrusion forming and cutting compared to save raw materials and parts with better performance, longer life. In this paper, a flange socket mold is designed and extrusion forming process is developed through numerical experiments, and the process finally achieved the design requirements.
\end{abstract}

\section{Introduction}

Because of the cold extrusion metal cold deformation with cold hardening characteristics during the extrusion process, the microstructure of metal materials is affected by many aspects of compressive stress after deformation, the material becomes dense and has a continuous flow of fiber, greatly improve the workpiece strength. On the other hand, usually cold extrusion material utilization can reach more than $80 \%$, while the size of workpiece forming precision can reach $8 \sim 9$, no longer need extra processing. In recent years, with the rapid development of cold extrusion technology, forming technology has been gradually replace the traditional mode of production of the cold extrusion, and it has good prospects for large batch production of parts. Based on the flange holder part structure the design characteristics of the composite extrusion and cold upsetting extruding forming process, and by means of numerical simulation analysis of the process, finally the forming die is designed.

Setting of forming process

Cold extrusion with flange blank holder forming process design is as follows: under the bar billet lubricating treatment - anti extrusion - annealing and pickling - lubricating - extrusion forming by upsetting extrusion. Extrusion process as shown in Figure 1.

\section{Parts and simulation parameters setting}

Parts of the aluminum alloy with flange socket, thin bowl parts. Its material is of $2 \mathrm{~A} 12$ aluminium and mechanical properties: $\sigma b \geq 520 \mathrm{MPa} 、 \delta \geq 5 \%$, this part of their internal and external shape size as shown in Figure 2, with a cylindrical surface and the bottom surface of the flange socket to keep certain squareness. Due to the surface and any surface contact, so the inner wall of the product is not processing. According to the symmetry of parts, this paper chooses 1 / 4 of the actual parts to simulate the forming, forming symmetrical superposition can be obtained throughout the complete parts.

\section{Introduction of finite element model}

The paper uses the powerful DEFORM-3D bulk metal forming simulation software, using a 3D modeling software to set up geometric model and its assembly of the punch, die, blank, such as shown in Figure 3, and to *.STL format will import DEFROM-3D software, analog pre-processing settings. 

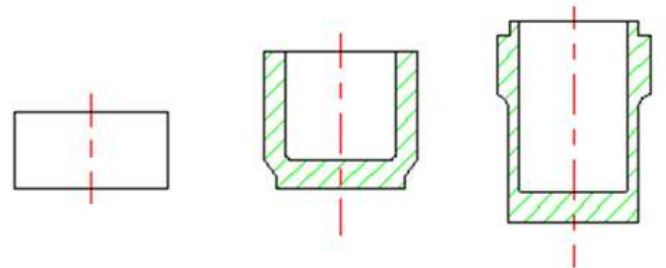

Fig.1 Extrusion forming process

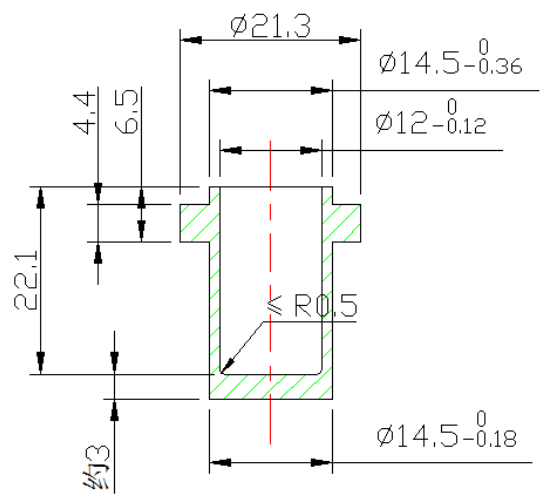

Fig.2 Part drawing

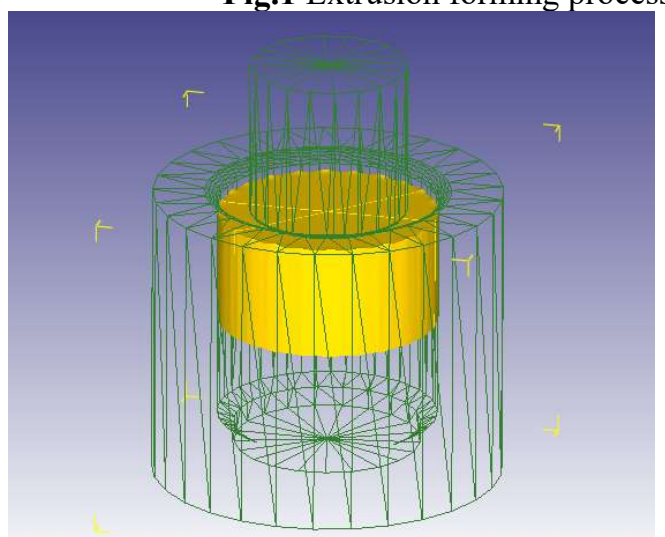

Fig.3 Assembly model
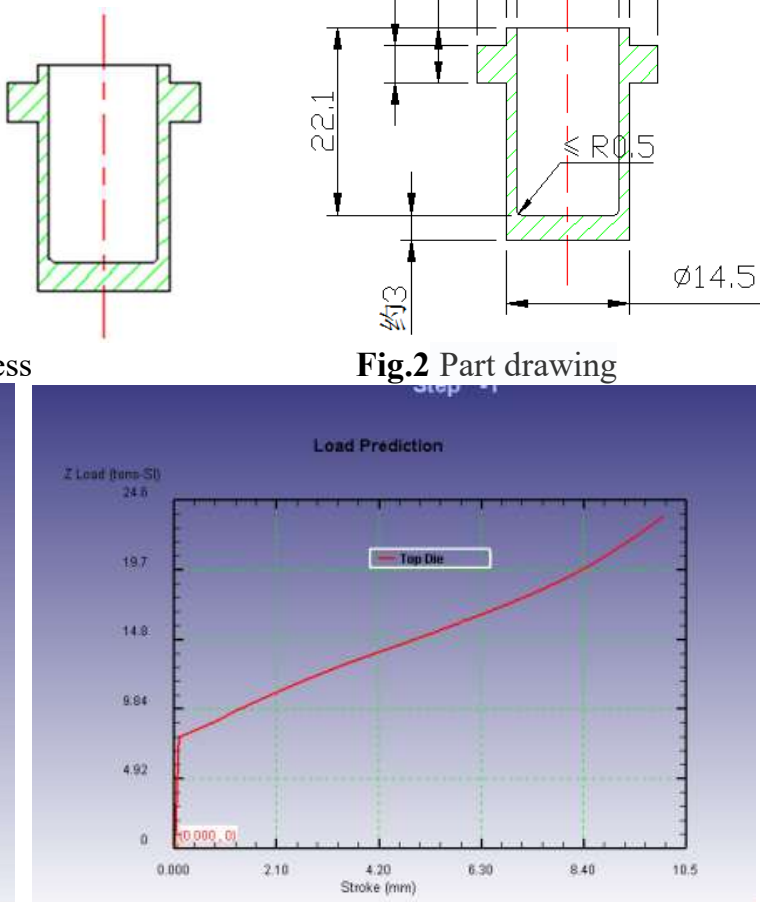

Fig.4Travel load chart

\section{Parameters and conditions used in simulation}

(1) Simulation is blank extrusion deformation, so the blank property is defined as the plastic (Plastic) material, for 2A12 aluminium alloy.

(2)The mold properties are defined as rigid (Rigid), the cold extrusion temperature is room temperature, and the system is maintained at 20 degrees.

(3) The extrusion speed is $10 \mathrm{~mm} / \mathrm{s}$.

(4) Due to the model of the die and the blank, the stress distribution in the extrusion process is also axial symmetry. The mesh is divided into 41288 small grids, which are based on the model with the smallest size 0.5 .

(5) The process of extrusion stroke is about $26 \mathrm{~mm}$.

\section{Simulation results and analysis}

Extrusion process and travel load curve analysis. After the DEFORM-3D numerical simulation calculation, get as shown in Figure 4 of the stroke load chart.

1) Comparative analysis of squeezing pressure:

In time $=0$ time $=0.450$, load with punch under pressure rises quickly. On the second stage, the metal is in stable deformation stage, and load values are rising steadily. Maximum load value is about 24.6 tonnes.

2) Forming process

The whole forming process can be divided into three stages, and the blank state of each stage is shown in Figure 5.

Time 1 stage: Punch lug boss part is pressed into the blank anti cold extrusion, also on the blank were preliminary upsetting value of load with the punch under pressure rises exponentially.

Time2 stage: Blank extrusion are mainly consists of two parts, on the one hand with the punch press blank to be upsetting, until the die sleeve wall and close contact; on the other hand, upsetting of the blank began from die out.

Time3 stage: Blank is in stable upsetting extrusion deformation stage. With the punch press, load 
value will continue to rise, this is due to the phase of the load are mainly composed of three parts: overcome the metal deformation resistance of loading, non deformation between the district and the die sleeve wall friction and blank and the outlet part of the friction. With the punch constantly under pressure, the ram pressure also reached the highest.
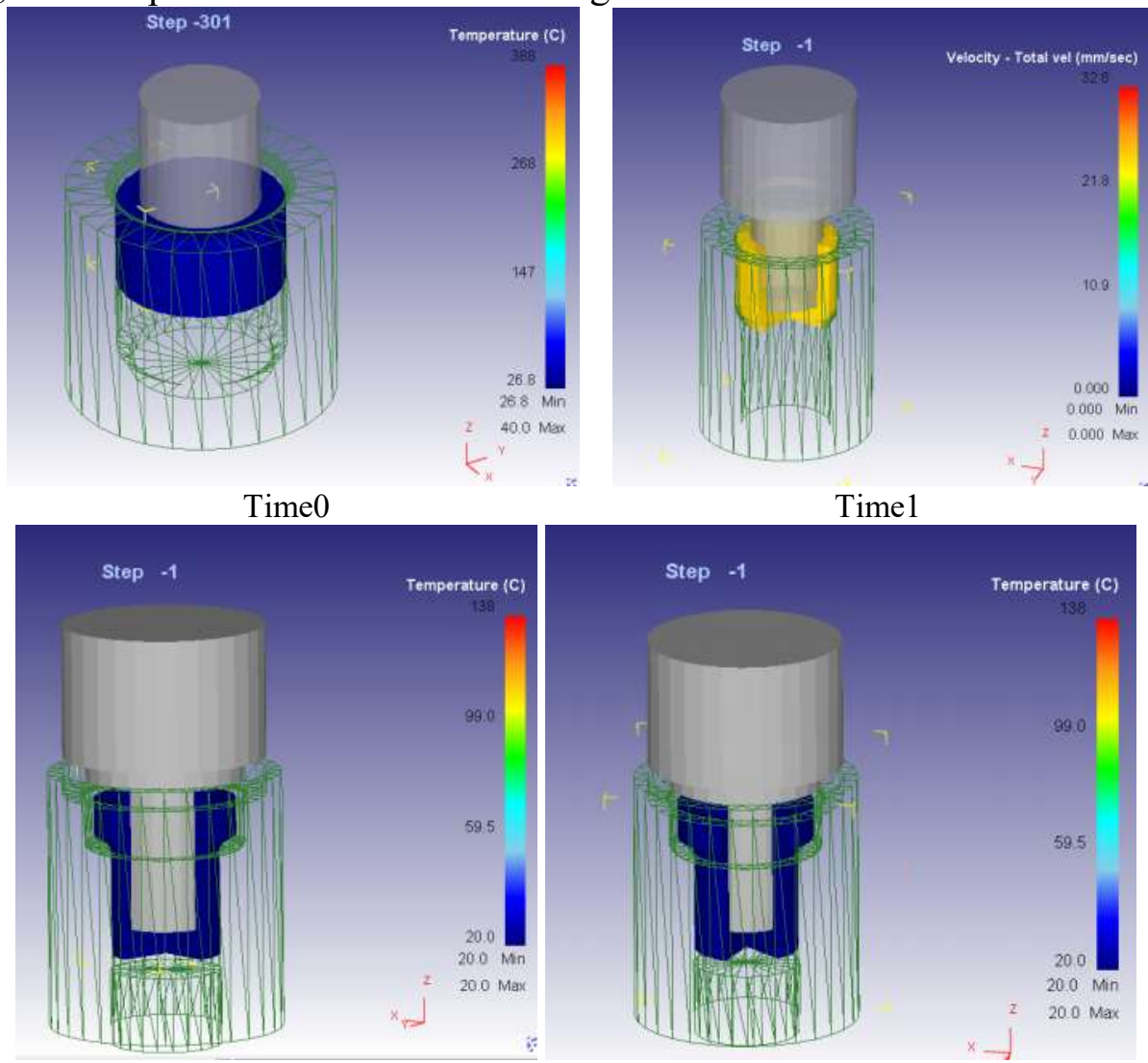

Time1

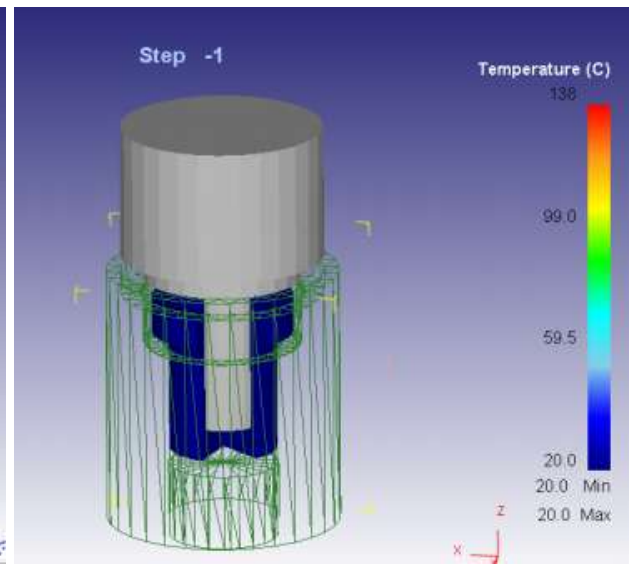

Time2

Time3

Fig.5 Analysis diagram of blank state at each stage

Analysis of metal flow in the process of extrusion. In metal extrusion process, the blank in different parts of the metal flow velocity magnitude and direction always changes. With the analysis methods can be divided into three stages to analysis, as shown in Figure 6 for the metal in the extrusion in the three different stages of the process flow.
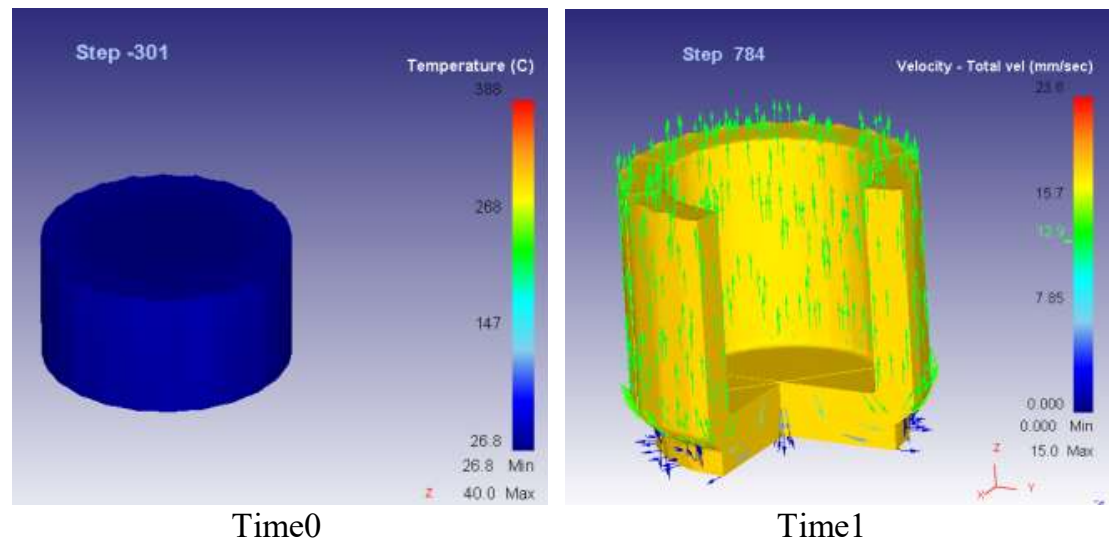


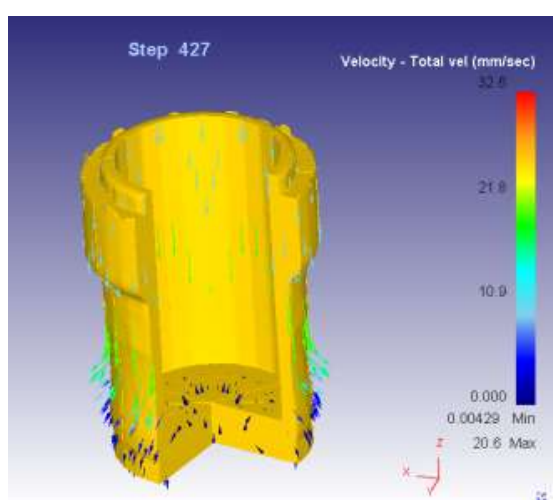

Time2

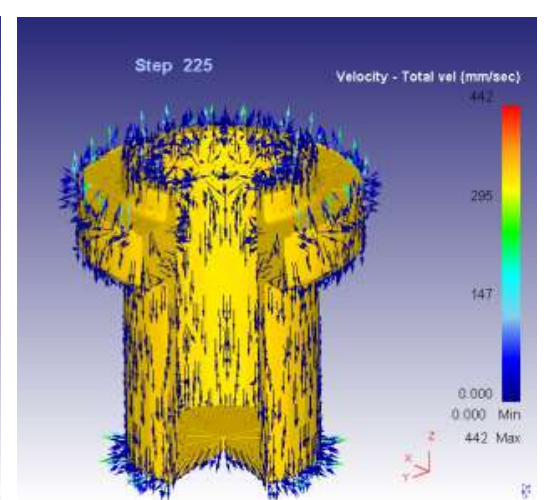

Time3

Fig.6 Analysis of metal flow at each stage

Specific analysis is as follows: Time1:Punch began pressing blank, blank flows under the punch recess, the limit velocity appears in the billet and the upper punch contact part.

Time2:A portion of the metal for upsetting blank except the central part, to flow outward; Die part of the metal in the role of punch has begun to outward flow, due to the die area is small, so material flow rate is big.

Time3: Stable forming stage, material flow is relatively stable. Finally due to die inside the billet length will reach the limit value, and die parts to metal flow. Therefore, the flow velocity of the upsetting part blank increased rapidly.

Analysis of equivalent stress in the process of forming. The stress distribution in the forming process is shown in Figure 7.
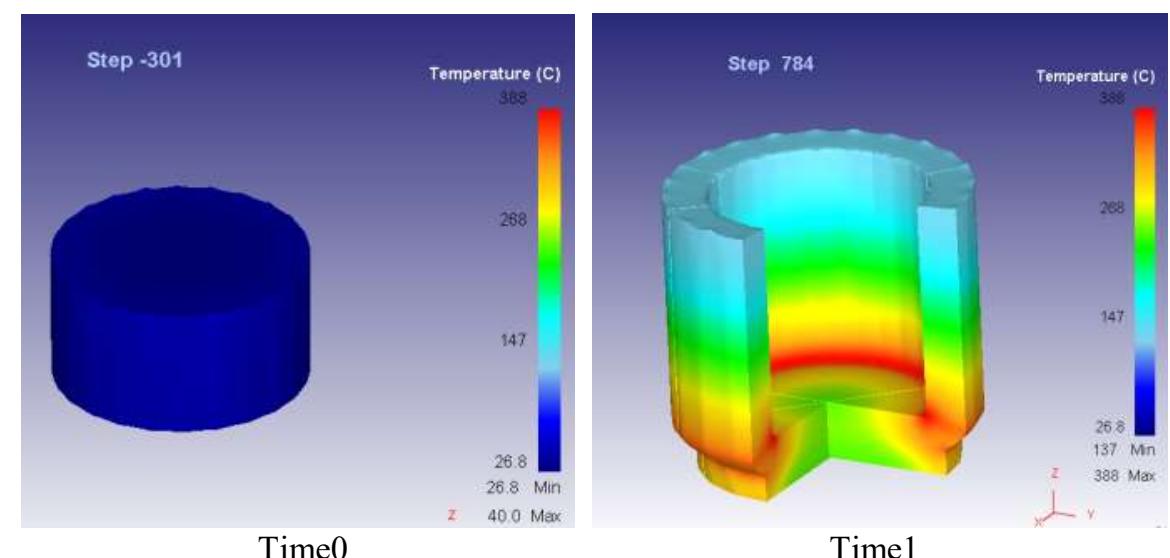

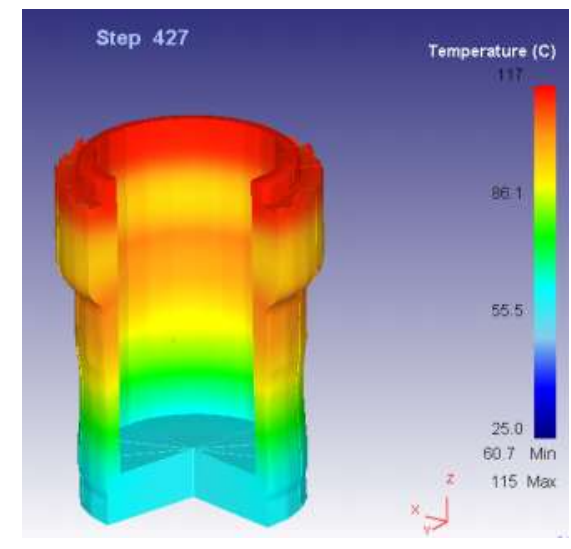

Time2

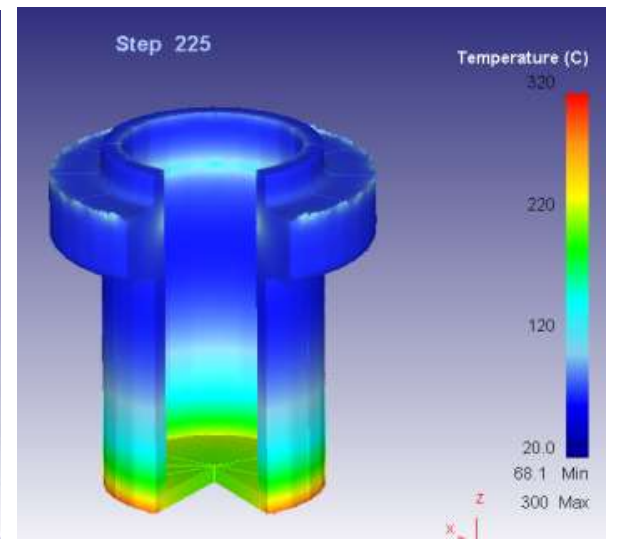

Time3

Fig.7 Stress distribution diagram

In initial stage of forming, due to the blank in upsetting and the transitional stage, the stress distribution is more uniform. The blank and punch contact stress is more concentrated, reaches a maximum value $843 \mathrm{MPa}$.Into the stable forming stage, straight tube billets in three to the state of compression, stress larger but more uniform; and die part of the metal is in free state, so its stress 
value is smaller. Forming at the end of the stress distribution change is not big, but due to the load value of reduced peak force is also slightly reduced, about $840 \mathrm{MPa}$.

\section{Design of press die upsetting}

The design of the parts for aluminum alloy with flange holder, its final forming by upsetting extrusion, due to the production of the part is very good accuracy to maintain certain coaxial degree, so the mold must be a guide device. Design of upsetting extrusion mould is shown in Figure 8.

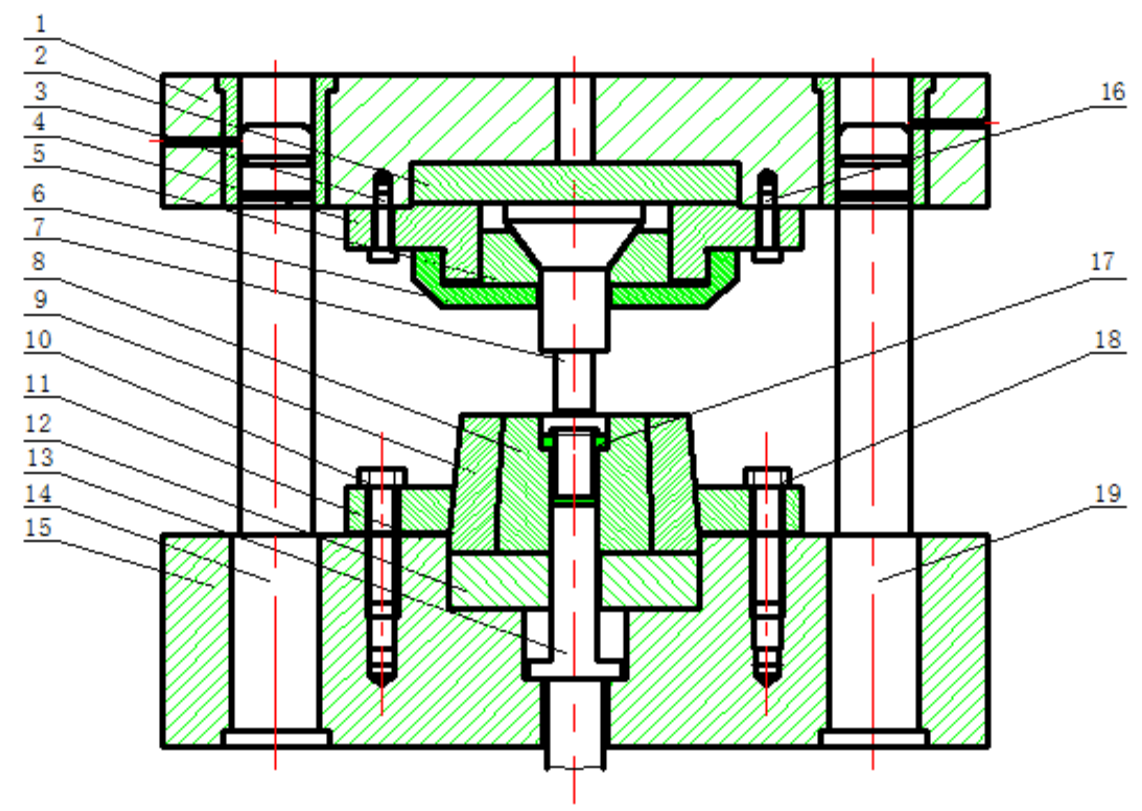

1 upper die seat; 2 upper mould seat plate; 3screw; 4 fixed ring; 5 retainer ring; 6 locking nut; 7 upper core; 8 lower core; 9 compressing ring; 10 bolt; 11 pressing ring; 12 lower die plate; 13 top rod; 14 guide pillar; 15 lower mould seat; 16 bolts; flange 17 lamp holder; 18 bolt; 19 guide pillar

\section{Summary}

Fig.8 Flanged socket cold upsetting extruding die

In this paper, the flange socket parts of the extrusion process design and numerical simulation tests and on the forming process of load curve, metal flow, equivalent stress were analyzed in accordance with the laws of metal plastic forming. The application of this technology due to the production practice, the workpiece quality good, size meet the prescribed requirements, material saving more than $50 \%$ and shorter working hours which is about one-third of the original, greatly reflects the superiority of the new technology.

\section{References}

[1] Xia, Guang. (2003). Thermal processing technology of straight spur gear cold forging process of the new value. Journal of thermal processing technology, (2): 22-23.

[2] Chen ,Yan, Liu etc. (2016 ).Automobile heat radiating fins of the cold extrusion forming numerical simulation. Journal of thermal processing technology, (5) :160-162.

[3] Chen, $\mathrm{Xu}$, Chen.( 2013).Influence of cold extrusion forming process on forming precision of cylindrical spur gear.Journal of casting technology, (1):115-117. 